\title{
Apigenin-induced apoptosis is enhanced by inhibition of autophagy formation in HCT116 human colon cancer cells
}

\author{
YUJIN LEE, BOKYUNG SUNG，YONG JUNG KANG，DONG HWAN KIM，JUNG-YOON JANG, \\ SEONG YEON HWANG, MINJUNG KIM, HYUN SOOK LIM, JEONG-HYUN YOON, \\ HAE YOUNG CHUNG and NAM DEUK KIM
}

\begin{abstract}
Division of Pharmacy, College of Pharmacy, Molecular Inflammation Research Center for Aging Intervention (MRCA), Pusan National University, Busan 609-735, Republic of Korea
\end{abstract}

Received December 30, 2013; Accepted February 24, 2014

DOI: $10.3892 /$ ijo.2014.2339

\begin{abstract}
Apigenin (4',5,7-trihydroxyflavone) is a natural flavonoid, shown to have chemopreventive and/or anticancer properties in a variety of human cancer cells. The involvement of autophagy in apigenin-induced apoptotic cell death of HCT116 human colon cancer cells was investigated. Apigenin induced suppression of cell growth in a concentrationdependent manner in HCT116 cells. Flow cytometric analyses indicated that apigenin resulted in $\mathrm{G} 2 / \mathrm{M}$ phase arrest. This flavone also suppressed the expression of both cyclin B1 and its activating partners, $\mathrm{Cdc} 2$ and $\mathrm{Cdc} 25 \mathrm{c}$, whereas the expression of cell cycle inhibitors, such as p53 and p53-dependent $\mathrm{p} 21^{C I P / / W A F I}$, was increased after apigenin treatment. Apigenin induced poly (ADP-ribose) polymerase (PARP) cleavage and decreased the levels of procaspase- $8,-9$ and -3 . In addition, the apigenin-treated cells exhibited autophagy, as characterized by the appearance of autophagosomes under fluorescence microscopy and the accumulation of acidic vesicular organelles by flow cytometry. Furthermore, the results of the western blot analysis revealed that the levels of LC3-II, the processed form of LC3-I, was increased by apigenin. Treatment with the autophagy inhibitor 3-methyladenine (3-MA) significantly enhanced the apoptosis induced by apigenin, which was accompanied by an increase in the levels of PARP cleavage. These results indicate that apigenin has apoptosis- and autophagy-inducing effects in HCT116 colon cancer cells. Autophagy plays a cytoprotective role in apigenin-induced apoptosis, and the combination of apigenin and an autophagy inhibitor may be a promising strategy for colon cancer control.
\end{abstract}

Correspondence to: Dr Nam Deuk Kim, Division of Pharmacy, College of Pharmacy, Pusan National University, Busan 609-735, Republic of Korea

E-mail: nadkim@pusan.ac.kr

Key words: apigenin, colon cancer cells, cell cycle, apoptosis, autophagy, 3-methyladenine

\section{Introduction}

Apigenin (4',5,7-trihydroxyflavone; Fig. 1A), a naturally occurring flavone, it is widely distributed in many fruits and vegetables such as parsley, onions, apples, tea and chamomile. In recent years, apigenin has been increasingly recognized as a cancer chemopreventive agent. The chemopreventive aspects of apigenin have been evaluated both in vitro and in vivo. Apigenin has been shown to be growth inhibitory in a variety of human cancer cell lines including colon, pancreatic, oral squamous, lung and leukemia cells (1-5). An important effect of apigenin is to increase the stability of the tumor suppressor p53 gene in normal cells. It has been shown that apigenin induced G2/M cell cycle arrest in colon cancer cells (1), and in vivo it is involved in p21 $1^{C I P / W A F I}$-independent pathway for inhibitory phosphorylation of p34 (Cdc2) and concomitant G2/M arrest in mouse keratinocytes (6). Apigenin was shown to induce apoptosis in a variety of cancer cells $(3,4,7,8)$. Apigenin has shown to inhibit tumor cell invasion and metastases by regulating the hypoxia-inducible factor 1- $\alpha$ protein level and to inhibit transforming growth factor $\beta$ 1-induced vascular endothelial growth factor expression in human prostate cancer cells (9). Moreover, apigenin has been reported to potentiate the effect of tumor necrosis factor-related apoptosis-inducing ligand, paclitaxel, ABT-263, 5-fluorouracil (5-FU) and cisplatin against various human cancers (10-13).

Autophagy, an evolutionarily conserved process, sequesters and degrades long-lived cellular proteins and organelles through the lysosomal machinery $(14,15)$. The purpose of autophagy is the recycling of cellular components to sustain metabolism under stress conditions such as nutrient deprivation and to prevent accumulation of damaged proteins and organelles (16). The first evidence for a role of autophagy in cancer was found by Liang et al (17). The autophagy-promoting activity of beclin-1 in human breast cancer cells is associated with inhibition of MCF7 cellular proliferation (17). It is reported that beclin-1, a phylogenetically conserved protein that is essential for autophagy, can inhibit tumorigenesis and is expressed at decreased levels in human breast carcinoma. Recent evidence indicates that the phosphoinositide 3-kinase (PI3K), Akt and mammalian target of rapamycin (mTOR) pathway, which is activated in many types of cancer (18) is important in autophagy regulation, especially through activating mTOR kinase, leading to suppression 
of autophagy (15). Recently, increasing evidence indicates that autophagy is closely associated with tumors. It participates as a tumor suppressor in tumor development in the early stages and as a proto-oncogene in advanced stages (19). Autophagy has been show to increase as a result of chemotherapy, leading the cancer cells to autophagic cell death (programmed cell death) (20). However, although autophagy is a potential therapeutic target in adjuvant chemotherapy, the exact role and the relationship of autophagy with cancer development and progression, autophagic cell death, and apoptosis in cancer are still unclear.

Colorectal cancer (CRC) is the third most common incident cancer among men and the second most frequent among women in worldwide (21). Although specific causes of colon cancer are not known, nutritional and environmental factors have been associated with the development of colon cancer. In Korea, incidence of CRC has significantly increased. Annual percentage changes in age-standardized incident rates were $6.2 \%$ in men and 6.8\% in women between 1999 and 2009 using the world standard population as a reference population. It is the second common cancer after stomach among men and the third most common after cancers of thyroid and breast among women in Korea $(22,23)$. Surgical resection currently remains the only curative treatment for CRC, however, it is unsatisfactory. This is because only $70 \%$ of colorectal tumors are resectable, $75 \%$ of which are curable, and many patients have to receive adjuvant chemotherapy (24). Due to the incomplete therapeutic options for colon cancer, there is a need to develop preventive treatment approaches for this malignancy. This study was conducted to investigate the ability of apigenin to induce apoptotic cell death and the ability of apigenin to induce autophagy in HCT116 human colon cancer cells, and whether inhibition of autophagy could potentiate the proapoptotic effect of apigenin.

\section{Materials and methods}

Reagents. Apigenin, acridine orange, 3-methyladenine (3-MA), and monoclonal antibody against $\beta$-actin were purchased from Sigma-Aldrich (St. Louis, MO, USA). Apigenin was dissolved in dimethylsulfoxide (DMSO) and stored at $-20^{\circ} \mathrm{C}$ before the experiments and dilutions were made in culture medium. 3-(4,5-dimethylthiazol-2-yl)-2,5-diphenyl tetrazolium bromide (MTT) was obtained from Amresco (Solon, OH, USA). Antibodies against beclin-1, Cdc2, Cdc25c, cyclin B1, p21, p53, poly (ADP-ribose) polymerase (PARP), caspase-3, caspase-8 and caspase-9 were purchased from Santa Cruz Biotechnology (Santa Cruz, CA, USA). Polyclonal antibody against LC3B was obtained from Cell Signaling Technology (Danvers, MA, USA). RPMI-1640, fetal bovine serum (FBS), and penicillinstreptomycin were purchased from HyClone (Logan, UT, USA).

Cell culture and apigenin treatment. The human colorectal cancer cell line HCT116 was purchased from the American Type Culture Collection (Manassas, VA, USA) and maintained at $37^{\circ} \mathrm{C}$ in a humidified $95 \%$ air and $5 \% \mathrm{CO}_{2}$ in RPMI-1640 supplemented with $10 \% \mathrm{FBS}, 100 \mathrm{U} / \mathrm{ml}$ penicillin and $100 \mu \mathrm{g} / \mathrm{ml}$ streptomycin.

Assays for cell viability. The cell growth was determined by MTT assay. Cells were seeded in 6-well culture plate and incu- bated at $37^{\circ} \mathrm{C}$ for $24 \mathrm{~h}$. Then, cells were treated with different concentration of apigenin $(0-50 \mu \mathrm{M})$ for $24 \mathrm{~h}$. The cells were incubated in the dark with MTT reagent $(0.5 \mathrm{mg} / \mathrm{ml})$ at $37^{\circ} \mathrm{C}$ for $2 \mathrm{~h}$. Medium was removed, formazan was dissolved in DMSO and the absorbance at $540 \mathrm{~nm}$ was measured by using an ELISA plate reader.

Hoechst staining and observation of nuclear structure. Cells were washed twice with phosphate-buffered saline (PBS) and fixed with 3.7\% paraformaldehyde (Sigma-Aldrich) in PBS for $10 \mathrm{~min}$ at room temperature. Fixed cells were washed with PBS, and stained with $4 \mu \mathrm{g} / \mathrm{ml}$ Hoechst 33342 for $20 \mathrm{~min}$ at room temperature. The stained cells were washed twice with PBS and analyzed by a fluorescent microscope.

Cell cycle analyses by flow cytometry. Cells were harvested with trypsinization and washed once with PBS. After centrifugation, the cells were fixed in $70 \%$ ethanol at $-20^{\circ} \mathrm{C}$ overnight. Fixed cells were prepared for flow cytometry analysis by washing twice with PBS and then stained in propidium iodide (PI) (Sigma-Aldrich) solution (50 $\mu \mathrm{g} / \mathrm{ml}$ in PBS) for $30 \mathrm{~min}$ at room temperature in the dark. Flow cytometry analysis was performed on a Cytomic FC500 (Beckman Coulter, Istanbul, Turkey).

Western blot analysis. After apigenin treatment, cells were harvested and washed with cold PBS. Total cells were lysed in lysis buffer [ $40 \mathrm{mM}$ Tris ( $\mathrm{pH} 8.0$ ), $120 \mathrm{mMNaCl}, 0.5 \% \mathrm{NP}-40$, $2 \mu \mathrm{g} / \mathrm{ml}$ aprotinin, $2 \mu \mathrm{g} / \mathrm{ml}$ leupeptine and $100 \mu \mathrm{g} / \mathrm{ml}$ phenymethylsulfonyl fluoride (PMSF)]. After centrifugation, the supernatant was collected and protein concentration was determined by protein assay reagents (Bio-Rad, Hercules, CA, USA). Equal amount of protein extracts were denatured by boiling at $100^{\circ} \mathrm{C}$ for $5 \mathrm{~min}$ in sample buffer (Bio-Rad). The proteins were separated on subject to 6-15\% SDS-PAGE and transferred to polyvinylidenedi fluoride (PVDF) membrane. The membranes were blocked with $5 \%$ non-fat dry milk in Tris-buffered saline with Tween-20 buffer (TBS-T) $(20 \mathrm{mM}$ Tris, $100 \mathrm{mM} \mathrm{NaCl}, \mathrm{pH} 7.5$ and $0.1 \%$ Tween-20) for $1 \mathrm{~h}$ at room temperature. The membranes were washed $10 \mathrm{~min}, 4$ times with TBS-T buffer each for $10 \mathrm{~min}$ and incubated for $1 \mathrm{~h}$ with horseradish peroxidase-conjugated secondary antibodies (Santa Cruz Biotechnology). The membranes were washed once for $10 \mathrm{~min}, 4$ times with TBS-T buffer. Antigen-antibody complex were detected by the enhanced chemiluminescence (ECL) detection system (GE Healthcare, Piscataway, NJ, USA).

Annexin $V$ staining. The Annexin V-FITC is used to quantitatively determine the percentage of cells within a population that are actively undergoing apoptosis. Cells harvested were washed twice with cold PBS, suspended the cells in $1 \mathrm{X}$ binding buffer (BD Biosciences, San Diego, CA, USA). The counted cells were stained in PI and Annexin V-FITC solution (BD Pharmingen FITC Annexin V Apoptosis Detection kit, BD Biosciences) for $15 \mathrm{~min}$ at room temperature in the dark, and then, the stained cells were analyzed by flow cytometry.

Detection of autophagy with acridine orange staining. The formation of acidic vesicular organelles (AVOs) is a well-known feature of autophagy. Cells were seeded in 6-well culture plate and incubated at $37^{\circ} \mathrm{C}$ for $24 \mathrm{~h}$. Then, 
cells were treated with different concentration of apigenin $(0-50 \mu \mathrm{M})$ for $24 \mathrm{~h}$, and stained with acridine orange $(1 \mu \mathrm{g} /$ $\mathrm{ml}$ ) for $15 \mathrm{~min}$. Subsequently, cells were washed with PBS and examined under a fluorescent microscope. Depending on intracellular acidity, autophagic lysosomes appeared as orange/red fluorescent cytoplasmic vesicles, while the nuclei were displayed bright green. Alternatively, to quantify the development of AVOs, apigenin-treated cells were stained with acridine orange $(1 \mu \mathrm{g} / \mathrm{ml})$ for $15 \mathrm{~min}$, trypsinized, and then washed with PBS. The stained cells were then analyzed using a flow cytometer.

GFP-LC3 assay.HCT116 cells were transfected with LC3-GFP plasmid using Lipofectamine 2000 reagent (Invitrogen, Grand Island, NY, USA) according to the manufacturer's instructions. Cells were treated with 3-MA (5 mM), apigenin $(25 \mu \mathrm{M})$ or apigenin +3 -MA for $24 \mathrm{~h}$ and the formation of punctuate LC3-positive structures was observed by confocal microscopy.

Statistical analysis. Results are expressed as the mean \pm SD of three separate experiments and analyzed by Student's t-test, and considered significantly different at $\mathrm{p}<0.05$ or $\mathrm{p}<0.01$.

\section{Results}

Apigenin suppresses the growth of HCT116 cells. To investigate the growth inhibitory effect of apigenin (Fig. 1A), the MTT assay was performed in HCT116 cells. As shown in Fig. 1B, apigenin inhibited effectively cell proliferation of HCT116 cells in a concentration-dependent manner. The lower concentrations of apigenin $(6.25 \mu \mathrm{M})$ did not affect cell viability; however, the higher concentrations (25 and $50 \mu \mathrm{M}$ ) of apigenin significantly reduced the cell viability of HCT116 cells. Additional experiment was done to confirm the growth inhibitory activity of apigenin on HCT116 cells when analyzed by microscopic observations. As shown in Fig. 1C, cells treated with apigenin displayed distinct morphological changes compared with untreated cells. In particular, cells were rounded and cell number was decreased in a concentration-dependent manner after apigenin treatment.

Apigenin modulates cell cycle progression in HCT116 cells. To identify the mechanism responsible for apigenin-induced cell growth inhibition, cell cycle progression was evaluated by flow cytometry analysis, as shown in Fig. 2A, apigenin treatment caused a significant cell cycle arrest in the G2/M phase concentration-dependently. An accumulation of cells in $\mathrm{G} 2 / \mathrm{M}$ phase of $9.99,20.1,27.2$ and $29.5 \%$ was observed for $6.25,12.5,25$ and $50 \mu \mathrm{M}$, respectively, when compared with untreated cells (7.12\%). Next, we examined whether apigenin can modulate the expression of G2/M cell cycle regulators. Cells were treated with various concentrations of apigenin for $24 \mathrm{~h}$ and then the level of G2/M cell cycle regulatory proteins were examined by western blot analysis. As indicated in Fig. 2B, after the cells were exposed to apigenin, the levels of p53 and its downstream protein p21 2 CIPI/WAF1, a potent cyclin-dependent kinase (CDK) inhibitor in G1 and $\mathrm{G} 2 / \mathrm{M}$ phases, were increased in a concentration-dependent manner. Therefore, in agreement with previous findings

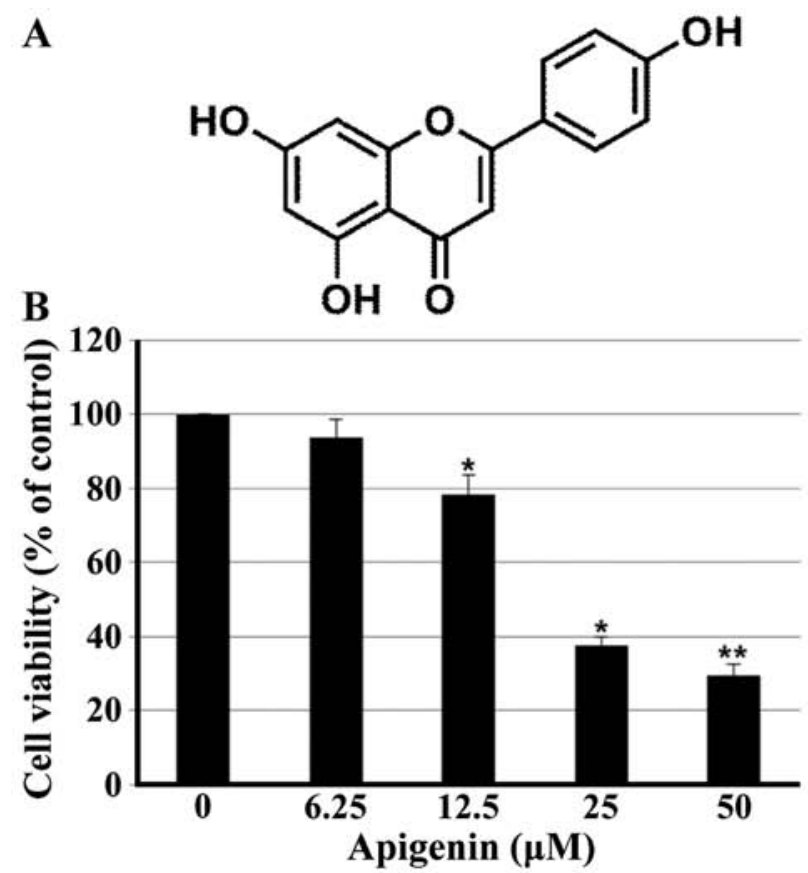

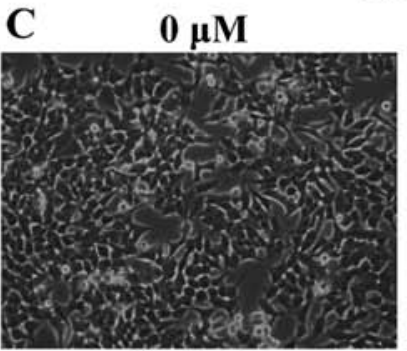

$12.5 \mu \mathrm{M}$
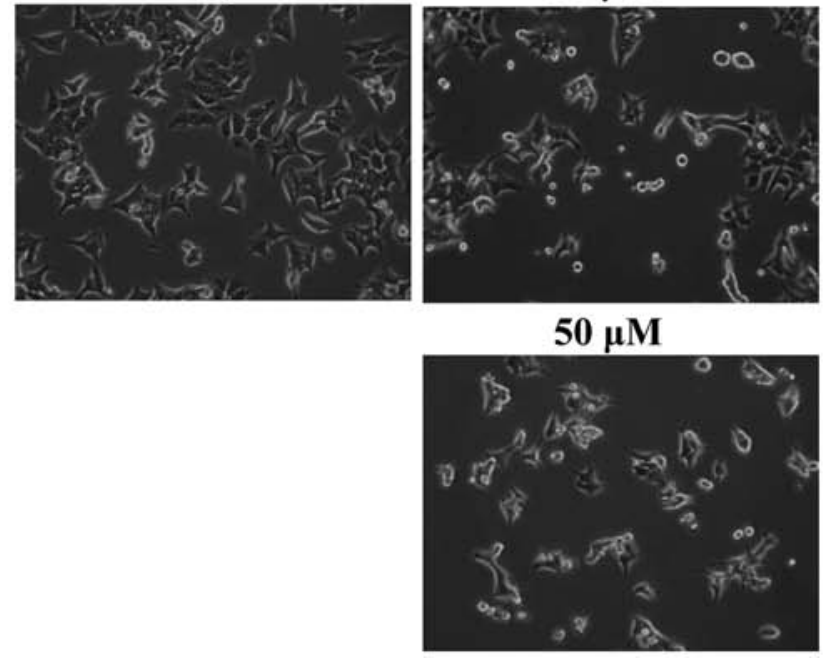

Figure 1. Effect of apigenin on cell viability of HCT116 cells. (A) Chemical structure of apigenin. (B) Cells were treated with increasing concentration of apigenin for $24 \mathrm{~h}$, and then MTT assay was performed to measure cell viability. Cell viability (\%) was expressed as a percentage compared to the untreated cells. The results are expressed as mean \pm SD $(n=6)$ of three separate experiments. The significance was determined by Student's t-test ${ }^{*} \mathrm{p}<0.05 ;{ }^{* *} \mathrm{p}<0.01$, compared with untreated cells. (C) Cells were treated with the indicated concentrations of apigenin for $24 \mathrm{~h}$, and then photographed by phase contrast microscopy at x400 magnification.

(Fig. 2A), apigenin treatment decreased $\mathrm{Cdc} 25 \mathrm{c}$ and its regulatory protein $\mathrm{Cdc} 2$ as well as cyclin B1 (Fig. 2B). These data 
A

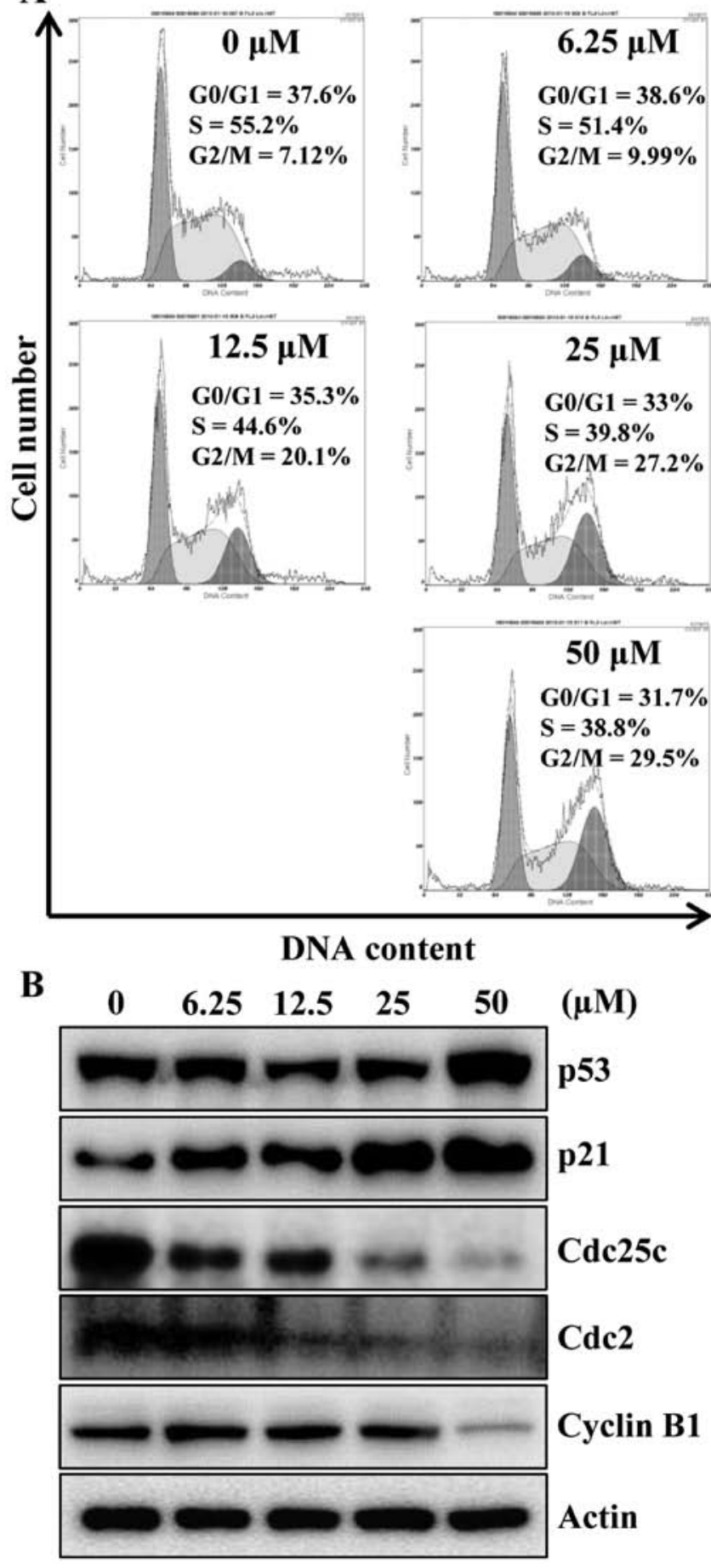

Figure 2. Effects of apigenin on the cell cycle and the levels of cell cycle regulator proteins in HCT116 cells. (A) Exponentially growing cells at $60-70 \%$ confluence were treated with apigenin $(0-50 \mu \mathrm{M})$ for $24 \mathrm{~h}$. The cells were fixed and digested with RNase, and then cellular DNA was stained with PI and analyzed by flow cytometry. The percentages of cells in G0/G1, $\mathrm{S}$ and $\mathrm{G} 2 / \mathrm{M}$ phases of cell cycle were calculated and are displayed within each histogram. (B) Cells were treated with apigenin $(0-50 \mu \mathrm{M})$ for $24 \mathrm{~h}$. Total cell lysates were prepared and subjected to $10-12 \%$ SDS-PAGE and electrophoretically transferred to PVDF membrane. Western blot analysis was conducted with indicated antibodies and ECL kits. Actin was used as an internal control. Representative results from three independent experiments are shown.

suggest the possibility that apigenin-induced growth inhibition of HCT116 cells was the result of G2/M arrest.

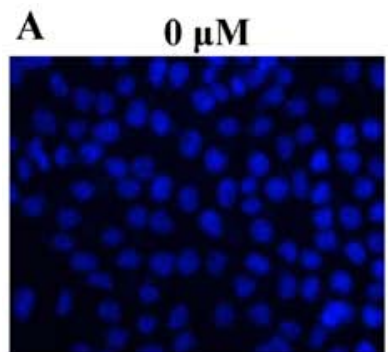

$12.5 \mu \mathrm{M}$
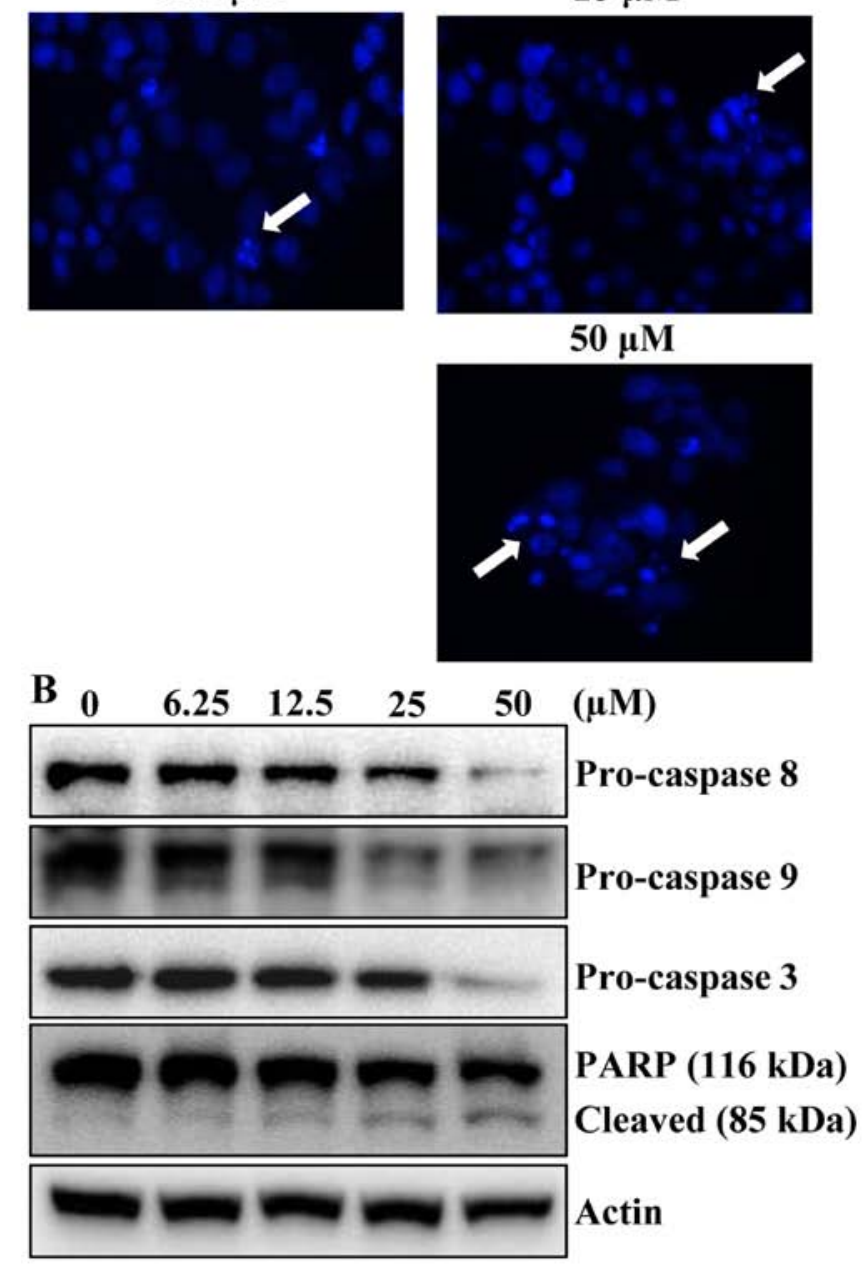

Figure 3. Effect of apigenin on apoptotic cell death in HCT116 cells. (A) HCT116 cells were treated with indicated concentration of apigenin for $24 \mathrm{~h}$, and then stained with a fluorescent DNA-binding dye, Hoechst 33342. The cells were observed and photographed under a fluorescence microscope using blue filter. Apoptotic cells (arrows). Magnification, x400. (B) HCT116 cells were treated with apigenin for $24 \mathrm{~h}$ and lysates were used to measure the levels of caspases and PARP (116 kDa). Representative results from three independent experiments are shown. Actin was used as an internal control.

Apigenin induces apoptosis in HCT116 cells. To determine whether the growth inhibitory effects of apigenin were due to apoptotic cell death, the morphological changes of cellular structures were assessed with Hoechst 33342 staining. The untreated control cells displayed intact nuclear structure, while cells were treated with apigenin resulted in chromosomal condensation and formation of apoptotic bodies, which are characteristics of programmed cell death (Fig. 3A, arrows). The effect of apigenin on apoptosis was further verified by western blot analysis. Apigenin treatment decreased the protein levels 

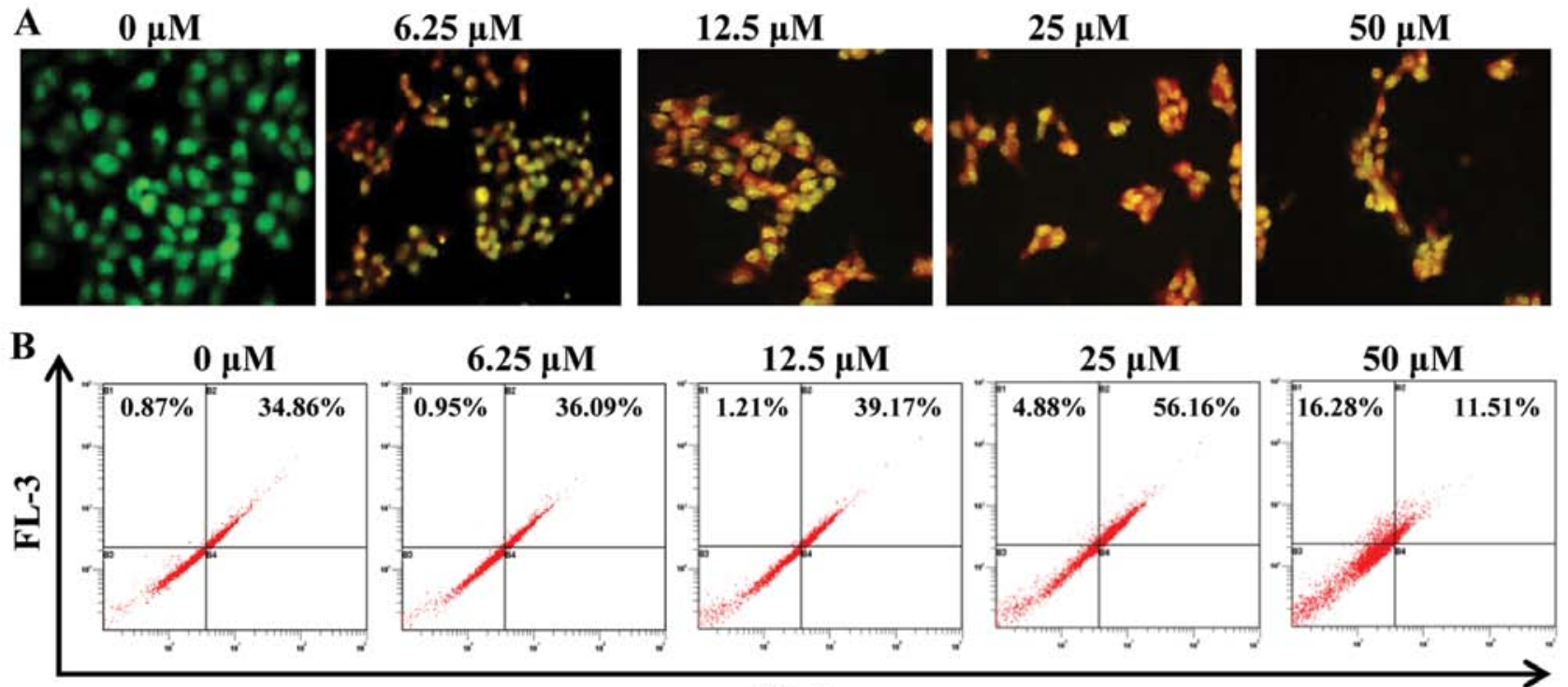

FL-1

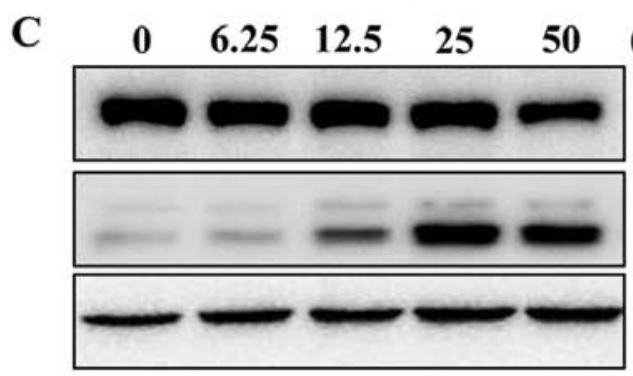

$(\mu \mathrm{M})$

\section{Beclin-1}

\section{LC3-I}

LC3-II

\section{Actin}
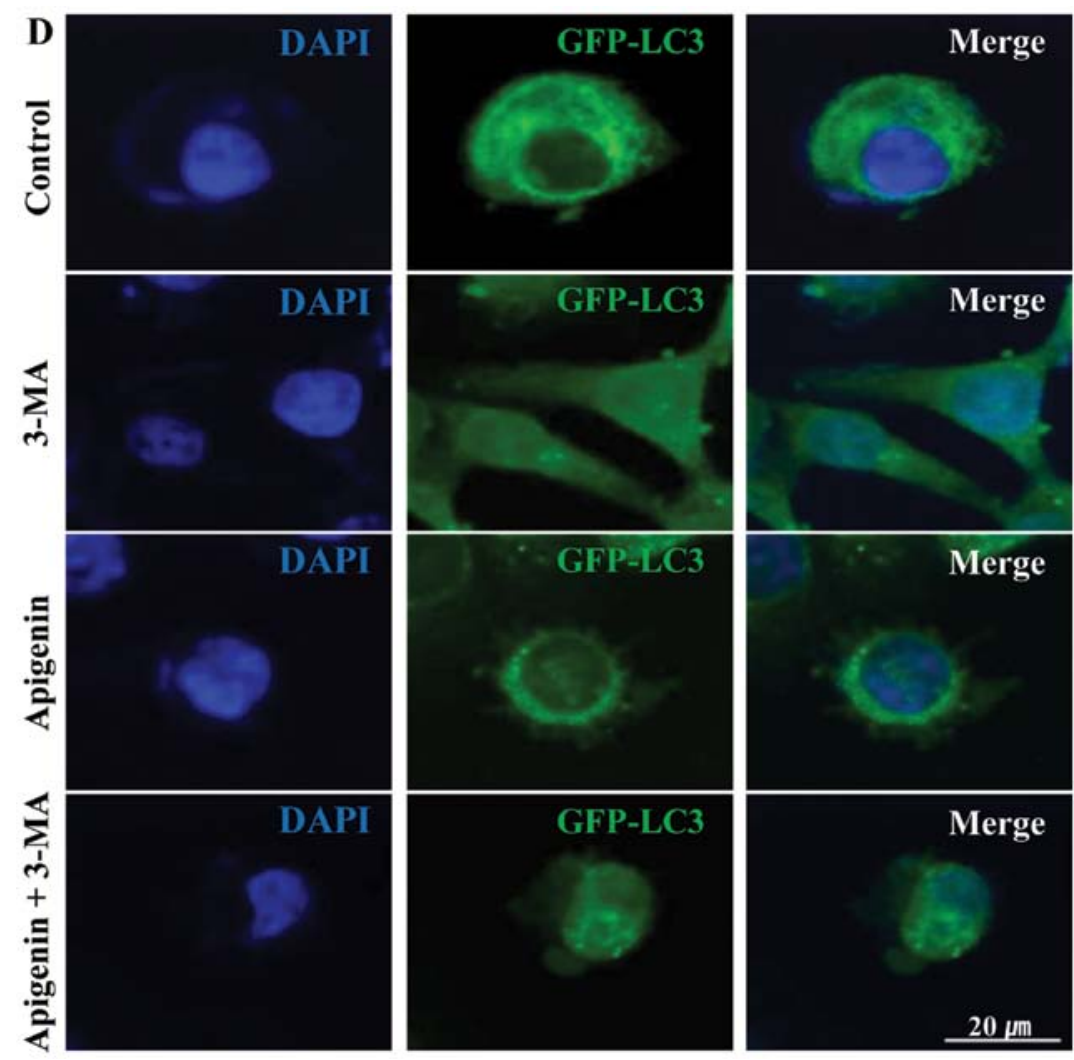

Figure 4. Induction of autophagy by apigenin in HCT116 cells. (A) Cells were treated with apigenin $(0-50 \mu \mathrm{M})$ for $24 \mathrm{~h}$, stained with acridine orange and then imaged by fluorescence microscopy to detect the acidic vesicular organelle (AVO) formation. (B) Flow cytometric analysis of the apigenin-treated cells after staining with acridine orange for the quantification of AVOs. (C) HCT116 cells were treated with various concentration of apigenin for $24 \mathrm{~h}$. Cells were lysed and the level of beclin-1 and LC3 proteins were analyzed by western blot analysis. Actin was used as an internal control. (D) After HCT116 cells were transfected with the LC3-GFP plasmid for $24 \mathrm{~h}$, the medium was replaced with media containing $25 \mu \mathrm{M}$ apigenin plus the presence or absence of 3-MA $(5 \mathrm{mM})$ and incubated for another $24 \mathrm{~h}$. The GFP-LC3 puncta formation was observed by confocal microscopy. Representative results from three independent experiments are shown. Bar, $20 \mu \mathrm{m}$. 
of procaspase- $8,-9$ and -3 in concentration-dependently. In accordance with the decrease of procaspases with consequent increase of the levels of active forms of caspases, the cleavage of PARP was increased in a concentration-dependent manner (Fig. 3B). These results suggested that apigenin induced apoptotic cell death in HCT116 cells.

Apigenin induces autophagy in HCT116 cells. Autophagy, an evolutionally conserved self-digestive process, is known as a cell survival mechanism during nutrient depletion and is essential to cellular homeostasis maintenance by facilitating the disposal of unfolded proteins and cellular constitutes (25). It has been reported that inhibition of autophagy has potential to promote apoptosis induced by several anticancer agents, which suggested that autophagy may play a protective role in cancer cells $(26,27)$. Recently, apigenin has been reported to induce autophagy in human breast cancer cells (28). To determine whether apigenin induces autophagy in HCT116 cells, we examined the effect of apigenin on the formation of acidic vesicular organelles (AVOs) in HCT116 cells. For this, we used acridine orange (AO), which accumulates in acidic cell compartments and displays bright red fluorescence (29). The formation of AVOs can be detected by fluorescence microscopy and quantified by flow cytometry. As shown in Fig. 4A, apigenin treatment caused progressive increase of AVO formation in HCT116 cells. In agreement with microscopic observation, flow cytometry analysis also showed a concentration-responsive increase in AVOs in apigenintreated cells as compared with their respective untreated control cells (Fig. 4B).

It is known that the beclin-1 level and LC3 conversion (LC3-I to LC3-II) are selective markers of autophagy. As shown in Fig. 4C, apigenin treatment markedly increased the expression of LC3-II, suggestive of autophagy induction. However, apigenin did not affect the expression of beclin-1 significantly. To further confirm the induction of autophagy by apigenin, we utilized fluorescence microscopy to examine autophagosome formation in HCT116 cells transiently expressing GFP-LC3 protein. Due to the conversion of LC3-I (a soluble form) to the LC3-II (a lipidized form), which associates with the membranes of autophagosomes (30), this conversion can be detected by observing the formation of punctate structures. Treatment of these cells for $24 \mathrm{~h}$ with apigenin resulted in relocalization of the GFP-LC3 protein to punctate cytoplasmic dots, indicators of autophagosome formation. Furthermore, co-treatment with apigenin and 3-MA, inhibits autophagy at initiation of double membrane encapsulation, significantly inhibiting GFP-LC3 dot formation in HCT116 cells (Fig. 4D).

Autophagy inhibition enhances apigenin-induced apoptosis in HCT116 cells. Accumulating data suggest that inhibition of autophagy may enhance chemosensitization in human cancer cells (31). Thus, we determined whether inhibition of autophagy could potentiate apigenin-induced apoptotic cell death. For this, we first performed Annexin V/PI staining to evaluate the effects of 3-MA on apigenin-induced apoptosis. Results indicated that apoptosis induction was $25 \%$ by apigenin, $23 \%$ by $3-\mathrm{MA}$, and $45.3 \%$ by the combination of the two agents (Fig. 5A). Furthermore, the alteration in the protein levels of LC3 and apoptotic proteins procaspase- $8,-9$ and -3 and PARP

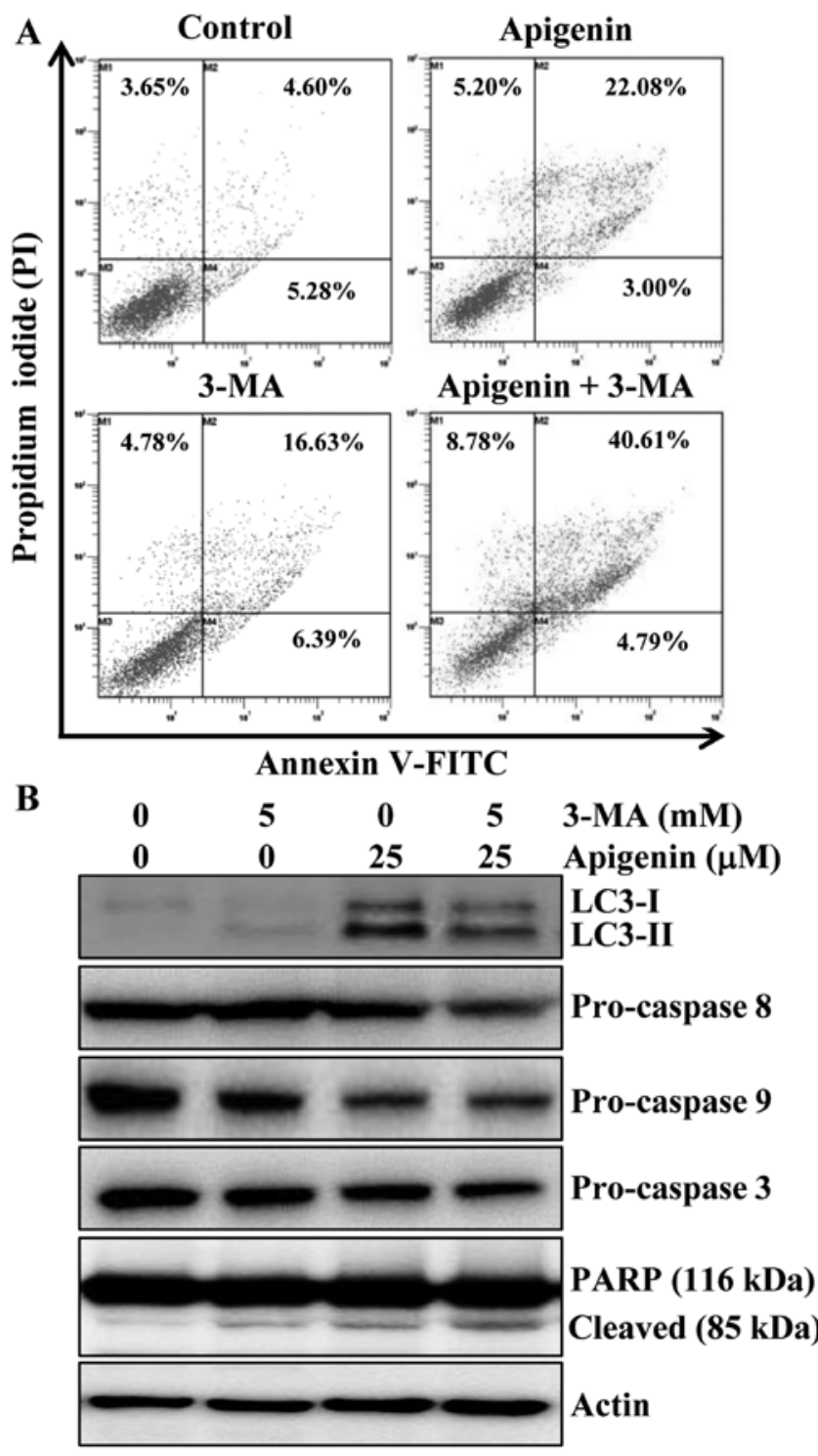

Figure 5. Effect of 3-MA on the activation of apoptosis by apigenin. (A) Cells were treated with apigenin $(25 \mu \mathrm{M}), 3-\mathrm{MA}(5 \mathrm{mM})$ alone or in combination for $24 \mathrm{~h}$, stained with Annexin V/PI, and the apoptotic cell death was analyzed using flow cytometry. (B) Cells were exposed to apigenin, 3-MA alone or in combination for $24 \mathrm{~h}$. Whole-cell lysates were prepared and analyzed by western blot analysis using antibodies against LC3, PARP, procaspase-3, -8 and -9 . Representative results from three independent experiments are shown. Actin was used as an internal control.

cleavage were also observed by western blot analysis. The protein level of LC3-II was increased by apigenin, however, addition of 3-MA abrogated the effect of apigenin on LC3-II induction (Fig. 5B). We also found that the combination of 3-MA and apigenin resulted in a significant increase in the level of PARP cleavage and decrease in procaspase $-3,-8$ and -9 compared to apigenin treatment alone (Fig. 5B). Altogether, these results indicated that inhibition of autophagy by 3-MA enhanced apigenin-induced cell death in HCT116 cells.

\section{Discussion}

Many studies have demonstrated that apigenin exhibits chemopreventive effects on various cancer cells. Apigenin has been 
reported to act via several mechanisms, including promotion of cell cycle arrest $(1,32)$, apoptosis and suppression of signal transduction (33). One of most obvious mechanisms of apigenin is to induce p53 tumor suppressor protein at the translational level, followed by $\mathrm{p} 21$ induction (34). In the present study, apigenin effectively suppressed the growth of HCT116 cells by cell cycle arrest and this growth inhibition was attributed to apoptotic cell death. Furthermore, an alteration in the ratio of Bax to Bcl-2 has been proposed to play an important role in anticancer agentinduced cell death (35). The effect of apigenin on Bcl-2 family protein is controversial. Several reports indicated that apigenin could upregulate Bax and down-modulate Bcl-2 expression in numerous cancer cell lines including lung and breast cancer $(4,28)$. However, in agreement with the report of Shao et al (12), we could not find any significant changes in levels of pro-apoptotic protein, Bax and anti-apoptotic protein, Bcl-2, in HCT116 cells (data not shown). The precise reason for this difference is not clear but cell type and conditions for experiment used may count for this discrepancy.

We found that apigenin induces autophagy in colon cancer cells. In the autophagic pathways, there are two molecular regulation mechanisms, $\mathrm{PI} 3 \mathrm{~K} /$ protein kinase $\mathrm{B}(\mathrm{Akt}) / \mathrm{mTOR}$ and class III PI3K signal transduction pathways. In the process of autophagy, the complex of beclin-1 and class III PI3K-dependent autophagy has an important function in mediating the localization of autophagy-related proteins to the preautophagosomal membrane (15). Autophagy has been shown by several antineoplastic agents in a great number of cancer cells, such as cervical carcinoma (36), glioma (37) or colon cancer cells (38). Our result showed progressive increase of LC3-II protein levels compared with the control cells by apigenin. At $25 \mu \mathrm{M}$ concentration, apigenin dramatically increased LC3-II, but higher concentration of apigenin $(50 \mu \mathrm{M})$ decreased LC3-II and beclin-1 levels. It is likely $50 \mu \mathrm{M}$ apigenin induced more cell death than $25 \mu \mathrm{M}$. The knockdown of beclin-1 caused slow cell growth compared with cells with normal expression of beclin-1 (39). Thus, we observed that apigenin induced both apoptosis and autophagy. This phenomenon may be explained by the effect of apigenin on the PI3K/Akt/mTOR pathway. It has been indicated that the anticancer effect of apigenin is related to the inhibition of the PI3K/Akt/mTOR pathway $(32,40)$, which is also an essential pathway that negatively regulates autophagy (41).

Furthermore, we found that autophagy inhibition using 3-MA pronounced apigenin-induced cell death. Adjusting autophagy appropriately may increase the cytotoxicity of anticancer drugs in tumor cells (42). A recent report indicated that 3-MA worked well with chemotherapeutic drugs by triggering apoptosis in some cancer cells (39). For example, autophagy inhibition by using 3-MA augmented chemotherapeutic effect of 5-FU in several in vitro models of human colon cancer (43). Therefore, we hypothesized that treatment of autophagy inhibitors might sensitize HCT116 cells to apigenin chemotherapy by improving the rate of apoptosis cell death induced by apigenin or by converting the autophagy process to an apoptotic process. It has been indicated that, inhibition of autophagy by 3-MA enhances the apoptosis in many cancer cells. The mitochondrial apoptotic pathway is a relatively important death receptor pathway for the induction of apoptosis by chemotherapeutic drugs (24).
In conclusion, apigenin suppressed growth of HCT116 cells in a concentration-dependent manner by causing G2/M cell cycle arrest. In addition, apigenin-treated cells exhibited inductions of apoptosis and autophagy. The inhibition of autophagy by 3-MA enhanced the apoptosis induced by apigenin through activations of pro-caspases- $8,-9$ and -3 and cleavage of PARP. These results provide evidence that inhibition of autophagy may be an effective way to improve the chemotherapy of anticancer agents against human colon cancer.

\section{Acknowledgements}

This research was supported by Basic Science Research Program through the National Research Foundation of Korea (NRF) funded by the Korea government (MSIP) (NRF-2009-0071649). This study was also financially supported by the National Research Foundation of Korea (NRF) grant funded by the Korea government (MSIP) (no. 2009-0083538). We thank Aging Tissue Bank for providing research information. The authors thank Mr. Kyoung-Pil Lee (Pusan National University) for helping with confocal microscopy.

\section{References}

1. Wang W, Heideman L, Chung CS, Pelling JC, Koehler KJ and Birt DF: Cell-cycle arrest at G2/M and growth inhibition by apigenin in human colon carcinoma cell lines. Mol Carcinog 28: 102-110, 2000.

2. Wu DG, Yu P, Li JW, et al: Apigenin potentiates the growth inhibitory effects by IKK-beta-mediated NF-kappaB activation in pancreatic cancer cells. Toxicol Lett 224: 157-164, 2014.

3. Maggioni D, Garavello W, Rigolio R, Pignataro L, Gaini R and Nicolini G: Apigenin impairs oral squamous cell carcinoma growth in vitro inducing cell cycle arrest and apoptosis. Int $\mathrm{J}$ Oncol 43: 1675-1682, 2013.

4. Das S, Das J, Samadder A, Boujedaini N and KhudaBukhsh AR: Apigenin-induced apoptosis in A375 and A549 cells through selective action and dysfunction of mitochondria. Exp Biol Med (Maywood) 237: 1433-1448, 2012.

5. Jayasooriya RG, Kang SH, Kang CH, et al: Apigenin decreases cell viability and telomerase activity in human leukemia cell lines. Food Chem Toxicol 50: 2605-2611, 2012.

6. McVean M, Weinberg WC and Pelling JC: A p21(waf1)independent pathway for inhibitory phosphorylation of cyclin-dependent kinase p34(cdc2) and concomitant $\mathrm{G}(2) / \mathrm{M}$ arrest by the chemopreventive flavonoid apigenin. Mol Carcinog 33: 36-43, 2002.

7. Zhu Y, Mao Y, Chen H, et al: Apigenin promotes apoptosis, inhibits invasion and induces cell cycle arrest of T24 human bladder cancer cells. Cancer Cell Int 13: 54, 2013.

8. Kim SH, Kang JG, Kim CS, et al: Apigenin induces c-Myc-mediated apoptosis in FRO anaplastic thyroid carcinoma cells. Mol Cell Endocrinol 369: 130-139, 2013.

9. Mirzoeva S, Kim ND, Chiu K, Franzen CA, Bergan RC and Pelling JC: Inhibition of HIF-1 alpha and VEGF expression by the chemopreventive bioflavonoid apigenin is accompanied by Akt inhibition in human prostate carcinoma PC3-M cells. Mol Carcinog 47: 686-700, 2008.

10. Horinaka M, Yoshida T, Shiraishi T, Nakata S, Wakada M and Sakai T: The dietary flavonoid apigenin sensitizes malignant tumor cells to tumor necrosis factor-related apoptosis-inducing ligand. Mol Cancer Ther 5: 945-951, 2006.

11. Xu Y, Xin Y, Diao Y, et al: Synergistic effects of apigenin and paclitaxel on apoptosis of cancer cells. PLoS One 6: e29169, 2011.

12. Shao H, Jing K, Mahmoud E, Huang H, Fang X and Yu C: Apigenin sensitizes colon cancer cells to antitumor activity of ABT-263. Mol Cancer Ther 12: 2640-2650, 2013.

13. Chan LP, Chou TH, Ding HY, et al: Apigenin induces apoptosis via tumor necrosis factor receptor- and Bcl-2-mediated pathway and enhances susceptibility of head and neck squamous cell carcinoma to 5-fluorouracil and cisplatin. Biochim Biophys Acta 1820: 1081-1091, 2012. 
14. Mizushima N: Autophagy: process and function. Genes Dev 21: 2861-2873, 2007

15. Shintani T and Klionsky DJ: Autophagy in health and disease: a double-edged sword. Science 306: 990-995, 2004.

16. Xie Z and Klionsky DJ: Autophagosome formation: core machinery and adaptations. Nat Cell Biol 9: 1102-1109, 2007.

17. Liang $\mathrm{XH}$, Jackson S, Seaman M, et al: Induction of autophagy and inhibition of tumorigenesis by beclin 1 . Nature 402 : 672-676, 1999

18. Vivanco I and Sawyers CL: The phosphatidylinositol 3-kinase AKT pathway in human cancer. Nat Rev Cancer 2: 489-501, 2002.

19. Ng G and Huang J: The significance of autophagy in cancer. Mol Carcinog 43: 183-187, 2005.

20. Gozuacik D and Kimchi A: Autophagy as a cell death and tumor suppressor mechanism. Oncogene 23: 2891-2906, 2004.

21. Ferlay J, Shin HR, Bray F, Forman D, Mathers C and Parkin DM: Estimates of worldwide burden of cancer in 2008: GLOBOCAN 2008. Int J Cancer 127: 2893-2917, 2010.

22. Jung KW, Park S, Kong HJ, et al: Cancer statistics in Korea: incidence, mortality, survival, and prevalence in 2009. Cancer Res Treat 44: 11-24, 2012

23. Shin A, Kim KZ, Jung KW, et al: Increasing trend of colorectal cancer incidence in Korea, 1999-2009. Cancer Res Treat 44: 219-226, 2012

24. Huerta S, Goulet EJ and Livingston EH: Colon cancer and apoptosis. Am J Surg 191: 517-526, 2006.

25. Kundu $\mathrm{M}$ and Thompson CB: Autophagy: basic principles and relevance to disease. Annu Rev Pathol 3: 427-455, 2008.

26. Lin JF, Tsai TF, Liao PC, et al: Benzyl isothiocyanate induces protective autophagy in human prostate cancer cells via inhibition of mTOR signaling. Carcinogenesis 34: 406-414, 2013.

27. Cheng P, Ni Z, Dai X, et al: The novel BH-3 mimetic apogossypolone induces Beclin-1- and ROS-mediated autophagy in human hepatocellular carcinoma cells. Cell Death Dis 4: e489, 2013.

28. Cao X, Liu B, Cao W, et al: Autophagy inhibition enhances apigenin-induced apoptosis in human breast cancer cells. Chin J Cancer Res 25: 212-222, 2013.

29. Paglin S, Hollister T, Delohery T, et al: A novel response of cancer cells to radiation involves autophagy and formation of acidic vesicles. Cancer Res 61: 439-444, 2001.

30. Klionsky DJ, Abeliovich H, Agostinis P, et al: Guidelines for the use and interpretation of assays for monitoring autophagy in higher eukaryotes. Autophagy 4: 151-175, 2008.
31. Carew JS, Nawrocki ST and Cleveland JL: Modulating autophagy for therapeutic benefit. Autophagy 3: 464-467, 2007.

32. Shukla S and Gupta S: Apigenin-induced cell cycle arrest is mediated by modulation of MAPK, PI3K-Akt, and loss of cyclin D1 associated retinoblastoma dephosphorylation in human prostate cancer cells. Cell Cycle 6: 1102-1114, 2007.

33. Van Dross RT, Hong $X$ and Pelling JC: Inhibition of TPA-induced cyclooxygenase-2 (COX-2) expression by apigenin through downregulation of Akt signal transduction in human keratinocytes. Mol Carcinog 44: 83-91, 2005.

34. King JC, Lu QY, Li G, et al: Evidence for activation of mutated p53 by apigenin in human pancreatic cancer. Biochim Biophys Acta 1823: 593-604, 2012

35. Adams JM and Cory S: The Bcl-2 apoptotic switch in cancer development and therapy. Oncogene 26: 1324-1337, 2007.

36. Harhaji-Trajkovic L, Vilimanovich U, Kravic-Stevovic T, Bumbasirevic V and Trajkovic V: AMPK-mediated autophagy inhibits apoptosis in cisplatin-treated tumour cells. J Cell Mol Med 13: 3644-3654, 2009.

37. Nishikawa T, Tsuno NH, Okaji Y, et al: Inhibition of autophagy potentiates sulforaphane-induced apoptosis in human colon cancer cells. Ann Surg Oncol 17: 592-602, 2010.

38. Galluzzi L, Aaronson SA, Abrams J, et al: Guidelines for the use and interpretation of assays for monitoring cell death in higher eukaryotes. Cell Death Differ 16: 1093-1107, 2009.

39. Fang J, Xia C, Cao Z, Zheng JZ, Reed E and Jiang BH: Apigenin inhibits VEGF and HIF-1 expression via PI3K/AKT/p70S6K1 and HDM2/p53 pathways. FASEB J 19: 342-353, 2005.

40. Kim J, Kundu M, Viollet B and Guan KL: AMPK and mTOR regulate autophagy through direct phosphorylation of Ulk1. Nat Cell Biol 13: 132-141, 2011

41. Shingu T, Fujiwara K, Bogler O, et al: Inhibition of autophagy at a late stage enhances imatinib-induced cytotoxicity in human malignant glioma cells. Int J Cancer 124: 1060-1071, 2009.

42. Li J, Hou N, Faried A, Tsutsumi S and Kuwano H: Inhibition of autophagy augments 5-fluorouracil chemotherapy in human colon cancer in vitro and in vivo model. Eur J Cancer 46: 1900-1909, 2010

43. Li J, Hou N, Faried A, Tsutsumi S, Takeuchi T and Kuwano H: Inhibition of autophagy by 3-MA enhances the effect of 5-FU-induced apoptosis in colon cancer cells. Ann Surg Oncol 16: 761-771, 2009. 